\section{Reply to C. Falci et al}

We thank Falci et $\mathrm{al}^{1}$ for their comments, which give us an opportunity to discuss some of the methodologic aspects of our study ${ }^{2}$ in greater detail. We are also interested to see the final results of their similar trial, ${ }^{3}$ because the analysis of preliminary findings of an ongoing study can sometimes be misleading.

A major issue is certainly the method of administering Vulnerable Elders Survey-13 (VES-13) and comprehensive geriatric assessment (CGA). Because elderly patients often have difficulty in completing a self-reported questionnaire such as VES-13, ${ }^{4}$ we employed a physician-assisted assessment, even though this undoubtedly affected the time-saving characteristics of the questionnaire itself. To minimize possible investigator-related biases, CGA was administered by an independent physician before any other questionnaire, including VES-13.

Another aspect worth considering is the choice of the activities of daily living (ADLs) - and even more so the instrumental ADLs (IADLs) - score indicating state of dependency, which is particularly important, because it influences patients' subsequent clinical management. Because there is a lack of conclusive data from prospective investigations, we decided to adopt the criteria of Bernardi et al, ${ }^{5}$ who used an IADL cutoff value of five or fewer regardless of sex as defining the need for tailored treatment. In our experience, physician-guided administration of IADLs makes it possible to assess appropriately activities such as cooking and doing the laundry, which men are potentially capable of doing even if they often do not actually do them. It is for this reason that we believe a cutoff value of four can underestimate the frequency of disability in men. As far as the possible impact of tumor stage on VES-13 is concerned, although our study population was correctly sized in relation to pre-established objectives, we did not make any subgroup analyses (eg, on the basis of tumor stage) to avoid inconsistencies resulting from inadequate sample size. Although a higher prevalence of disability has been reported in similar studies, 6,7 the 419 consecutive unselected patients assessed in an oncologic department of a general hospital in our series ${ }^{2}$ were likely representative of our urban area. The satisfactory sensitivity and specificity of VES-13 we reported were more likely to have resulted from the characteristics of the instrument itself than from the patient mix of the sample. The negative predictive value, which is an essential requirement for a reliable screening tool, was high (91.2\%), suggesting the validity of the test in this setting.

In conclusion, we agree that clinicians should be cautious when using VES-13 as a substitute for CGA. On the basis of our findings and as stated in our report, ${ }^{2}$ we believe that VES-13 should instead be used as a screening tool to evaluate the functional status of elderly patients with cancer.

\section{Andrea Luciani}

San Paolo Hospital, Milan, Italy

\section{Irene Floriani}

Istituto Mario Negri, Milan, Italy

\section{Paolo Foa}

San Paolo Hospital; and University of Milan, Milan, Italy

\section{AUTHORS' DISCLOSURES OF POTENTIAL CONFLICTS OF INTEREST}

The author(s) indicated no potential conflicts of interest.

\section{REFERENCES}

1. Falci $C$, Brunello $A$, Monfardini S: Detecting functional impairment in older patients with cancer: Is Vulnerable Elders Survey-13 the right prescreening tool? An open question. J Clin Oncol 28:e665-e666, 2010

2. Luciani $A$, Ascione $G$, Bertuzzi $C$, et al: Detecting disabilities in older patients with cancer: Comparison between comprehensive geriatric assessment and Vulnerable Elders Survey-13. J Clin Oncol 28:2046-2050, 2010

3. Falci $C$, Basso U, Fiduccia $P$, et al: Is Vulnerable Elders Survey 13 (VES-13) a sensitive and specific screening tool for identifying vulnerable/frail elderly cancer patients compared to full comprehensive geriatric assessment (CGA)? Crit Rev Onc Hemat 72:S19-S20, 2009 (abstr P4)

4. Saliba D, Elliott M, Rubenstein LZ, et al: The Vulnerable Elders Survey: A tool for identifying vulnerable older people in the community. J Am Geriatr Soc Dec 49:1691-1699, 2001

5. Bernardi D, Milan I, Balzarotti M, et al: Comprehensive geriatric evaluation in elderly patients with lymphoma: Feasibility of a patient-tailored treatment plan. J Clin Oncol 21:754, 2003; author reply 755

6. Kellen E, Bulens $P$, Deckx L, et al: Identifying an accurate pre-screening tool in geriatric oncology. Crit Rev Oncol Hematol [epub ahead of print on January 6, 2010]

7. Mohile SG, Xian Y, Dale W, et al: Association of a cancer diagnosis with vulnerability and frailty in older Medicare beneficiaries. J Natl Cancer Inst 101:1206-1215, 2009

DOI: 10.1200/JCO.2010.30.7199; published online ahead of print at www.jco.org on August 16, 2010 